\title{
Cost Effectiveness of Ceftolozane/Tazobactam Compared with Meropenem for the Treatment of Patients with Ventilated Hospital-Acquired Bacterial Pneumonia and Ventilator-Associated Bacterial Pneumonia
}

\author{
Jaesh Naik · Laura Puzniak · Simone Critchlow • David Elsea • \\ Ryan James Dillon · Joe Yang (D) \\ Received: February 2, 2021 / Accepted: March 16, 2021 / Published online: April 9, 2021 \\ (c) The Author(s) 2021
}

\section{ABSTRACT}

Introduction: The clinical efficacy and safety of ceftolozane/tazobactam for the treatment of ventilated hospital-acquired bacterial pneumonia (vHABP) and ventilator-associated bacterial pneumonia (VABP) has been demonstrated in the phase III randomised controlled trial ASPECT-NP. However, there are no published data on the cost-effectiveness of ceftolozane/tazobactam for vHABP/VABP. These nosocomial infections are associated with high rates of morbidity and mortality, and are increasingly complicated by growing rates of resistance and the inappropriate use of antimicrobials. This study is to assess the cost-effectiveness of ceftolozane/tazobactam compared with meropenem for the treatment of vHABP/ VABP in a US hospital setting.

Methods: A short-term decision tree followed by a long-term Markov model was developed to

Supplementary Information The online version contains supplementary material available at https:// doi.org/10.1007/s40121-021-00436-4.

J. Naik · S. Critchlow

BresMed Health Solutions Ltd, Sheffield, UK

L. Puzniak · R. J. Dillon · J. Yang ( $₫)$

Merck \& Co., Inc., Kenilworth, NJ, USA

e-mail: joe.yang@merck.com

D. Elsea

BresMed America Inc., Las Vegas, NV, USA estimate lifetime costs and quality-adjusted lifeyears associated with ceftolozane/tazobactam and meropenem in the treatment of patients with vHABP/VABP. Pathogen susceptibility and clinical efficacy were informed by the Program to Assess Ceftolozane/Tazobactam Susceptibility (PACTS) database and ASPECT-NP, respectively. A US healthcare sector perspective was adopted, capturing direct costs borne by thirdparty payers or integrated health systems, and direct health effects for patients.

Results: In the confirmed treatment setting (post-susceptibility results), the incremental cost-effectiveness ratio for ceftolozane/tazobactam compared to meropenem was US $\$ 12,126$ per quality-adjusted life-year (QALY); this reduced when used in the early treatment setting (before susceptibility results) at $\$ 4775$ / QALY.

Conclusion: Ceftolozane/tazobactam represents a highly cost-effective treatment option for patients with vHABP/VABP versus meropenem when used in either the confirmed or early treatment setting; with increased cost-effectiveness shown in the early setting.

Keywords: Antimicrobial

resistance; Ceftolozane; Cost-effectiveness analysis; Hospital-acquired pneumonia; Mechanical ventilator 


\section{Key Summary Points}

\section{Why carry out this study?}

Ventilated hospital-acquired and ventilator-associated bacterial pneumonia (vHABP and VABP) are associated with a high mortality rate and intensive use of healthcare resource.

This study investigated the question whether ceftolozane/tazobactam could be a cost-effective treatment option for vHABP/VABP, given increased drug costs.

\section{What was learned from the study?}

Based on a model that synthesized evidence primarily from a Phase III trial and a global susceptibility surveillance database, it is estimated that ceftolozane/tazobactam could be a costeffective treatment option in both early (prior to culture test result) and confirmed treatment for vHABP/VABP, compared to meropenem.

Early treatment use of ceftolozane/tazobactam yielded more favorable economic and health outcomes than confirmed use of ceftolozane/tazobactam, by reducing the risk of initial inappropriate treatment.

\section{DIGITAL FEATURES}

This article is published with digital features, including a summary slide, to facilitate understanding of the article. To view digital features for this article go to https://doi.org/10.6084/ m9.figshare.14216423.

\section{INTRODUCTION}

Gram-negative pathogens are a major cause of hospital acquired infection, accounting for more than $30 \%$ of all healthcare-associated infections in the US [1]. Hospital-acquired bacterial pneumonia (HABP) is one of the most common hospital-acquired Gram-negative infections. HABP patients may experience acute respiratory failure and require mechanical ventilation (ventilated HABP, or vHABP) [2]. Ventilator-associated bacterial pneumonia (VABP) is the most common intensive care unit (ICU)acquired infection affecting approximately onethird of patients receiving mechanical ventilation [3]. Notably, higher all-cause mortality rates were found among patients with vHABP and VABP versus those with non-ventilated HABP [4].

The most frequently reported Gram-negative pathogens associated with HABP are Pseudomonas aeruginosa followed by Enterobacteriales [5]. These pathogens are often challenging to treat due to high rates of resistance against most commonly used antimicrobials $[6,7]$, and are designated by the World Health Organization as the highest 'critical' priority in need of new therapeutic options to counteract growing resistance to available treatments [8]. Declining effectiveness in antibiotics due to the growing resistance means that the risk of administering inappropriate treatment (where patients are treated with antibiotics with little or no in vitro activity against the causative pathogens) is rising $[9,10]$.

With global rates of antimicrobial resistance dangerously high, selecting an appropriate therapy is of paramount importance, and alternative agents for treating infections are sorely needed. Inappropriate therapy in HABP/VABP treatment has been associated with higher mortality rates, longer in-hospital length of stay (LOS), and increased healthcare costs [11-14]. Ceftolozane/tazobactam is a combination of a novel antipseudomonal cephalosporin (ceftolozane) and a well-established $\beta$-lactamase inhibitor (tazobactam), for treating serious Gram-negative bacterial infections including $\mathrm{HABP} / \mathrm{VABP}$ in patients 18 years and older (FDA approval June 2019) [12]. Ceftolozane/tazobactam met all primary clinical efficacy endpoints in a Phase III, double-blind, randomised study (ASPECT-NP) for the treatment of vHABP and VABP [15]. In addition, in the US sample of a global surveillance database, $96 \%$ of 
Enterobacteriaceae isolates were susceptible to ceftolozane/tazobactam, 91\% for extendedspectrum $\beta$-lactamase producing, non-carbapenem-resistant Enterobacteriaceae isolates, and $95.8 \%$ for $P$. aeruginosa $[16,17]$, indicating a broad susceptibility profile desirable for early treatment of HABP/VABP.

In addition to the established efficacy and safety profile of ceftolozane/tazobactam, it important to evaluate its economic value in combating HABP/VABP. This study aims to evaluate the cost-effectiveness of ceftolozane/tazobactam versus meropenem, by using clinical efficacy and susceptibility data in an economic model reflective of real-world $\mathrm{vHABP} / \mathrm{VABP}$ treatment scenarios.

\section{METHODS}

\section{Model Overview}

A cost-effectiveness model was created, comprising a short-term decision tree (depicting the period from HABP/VABP onset up to hospital discharge), and a long-term Markov component (projecting long-term outcomes after hospital discharge). The decision tree focused on antimicrobial therapy and patient response to therapy. Aligned with the ASPECT-NP trial population, the model considered adult patients with HABP/VABP and who were admitted to the ICU and ventilated. Patient response was classified into clinically 'cured', 'not cured', and 'death'. Patients cured in the decision tree moved to the long-term Markov model.

Within the short-term decision tree, two treatment settings were independently considered (Fig. 1): the early treatment setting and the confirmed treatment setting. In the early treatment setting (Fig. 1a), patients entering the model were treated with ceftolozane/tazobactam or meropenem prior to susceptibility profile being available. The time taken to receive confirmation of antimicrobial susceptibility or resistance was assumed to be 2 days from the date the culture was taken, which is based on clinical expert opinion [18]. Once test results were available, patients followed one of the three treatment pathways:

1. Causative pathogen(s) susceptible to early treatment remained on that treatment. If not cured by the early treatment, a subsequent treatment ensues.

2. Causative pathogen(s) susceptible to early treatment were de-escalated to a lower-cost alternative (more relevant to ceftolozane/tazobactam, which is associated with relatively high drug acquisition cost compared with meropenem).

3. Causative pathogen(s) not susceptible to early treatment (early inappropriate therapy) were switched to an alternative treatment.

In the confirmed treatment setting (Fig. 1b), patients received treatment with ceftolozane/tazobactam or meropenem when the susceptibility profile of causative pathogen was known by clinician (in line with ASPECTNP trial criteria). Patients who were alive but uncured moved to a subsequent treatment.

Patients who did not die during hospitalization move to the long-term Markov model (Fig. 1c), which was designed to capture lifetime costs and health-related quality of life. Cured patients will die at an age- and gender-specific rate, while uncured patients after receiving two lines of treatment are assumed to die within a year from index hospital admission (this assumption was tested in scenario analysis with alternative assumptions of $50 \%$ or $0 \%$ 1-year mortality rate).

\section{Model Settings}

A lifetime horizon (40 years) was adopted. In line with the Institute for Clinical and Economic Review reference case [19], a US healthcare sector perspective was used; direct costs incurred by third-party payers or integrated health systems and direct health effects for patients were therefore captured. Costs and quality-adjusted life-years (QALYs) were discounted at an annual rate of 3.00\% [19]. 


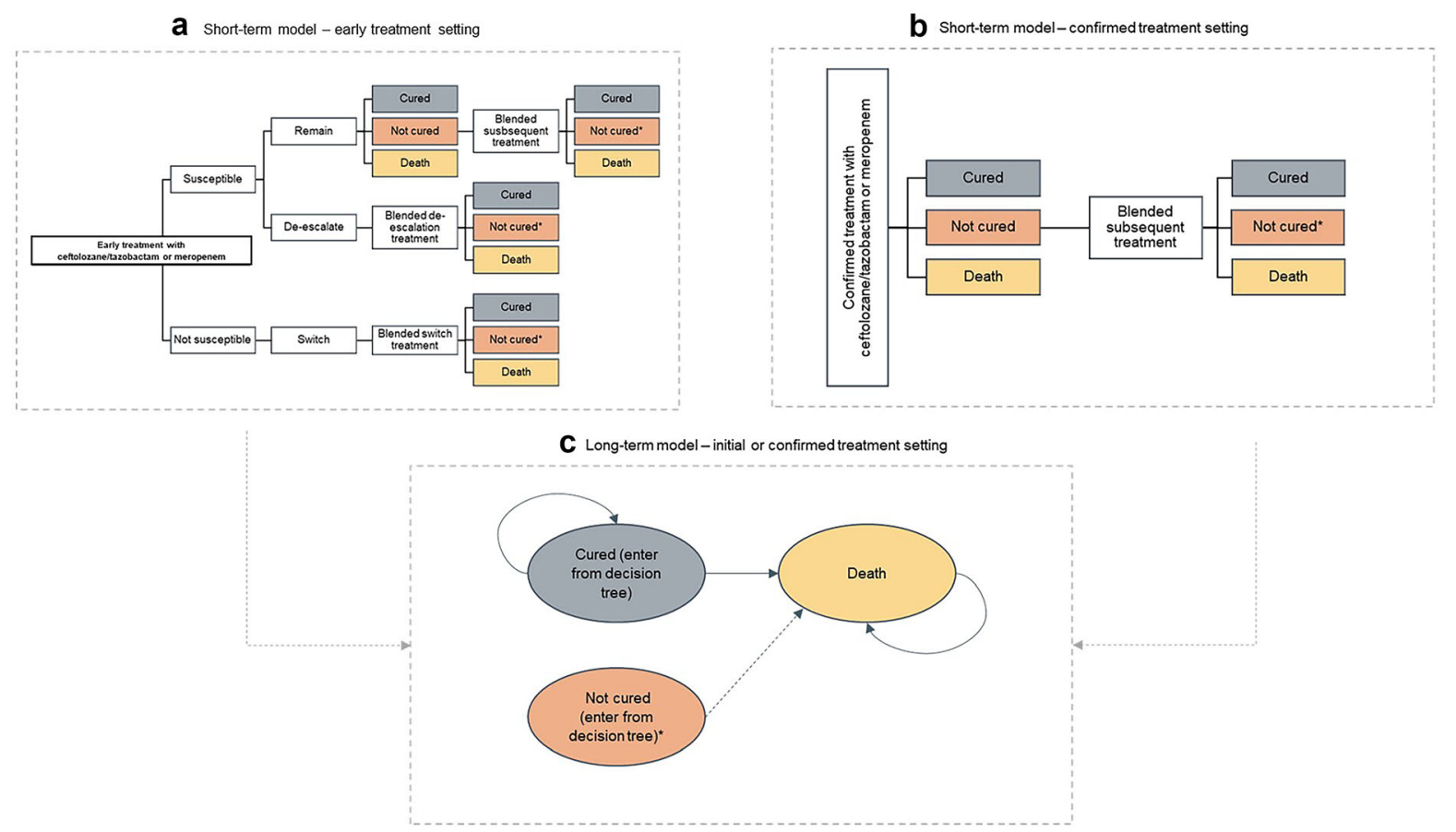

Fig. 1 Model structure diagram. * Patients who are alive but uncured at the end of the short-term decision tree are assumed to die within a year

\section{Treatments}

The model compared ceftolozane/tazobactam with meropenem in both the early and confirmed treatment settings, with a blend of subsequent treatments considered. The proportion of patients receiving each subsequent treatment was determined by susceptibility profiles from the Program to Assess Ceftolozane/Tazobactam Susceptibility (PACTS) database 2011-2018 conditional on the early treatment received [20]; the setting in which each subsequent treatment is commonly used (de-escalation, escalation or salvage); and, in cases of de-escalation, the prices of the subsequent treatments.

\section{Clinical Inputs}

Key input parameters discussed here and after are listed in Table 1. Clinical effectiveness for ceftolozane/tazobactam and meropenem was sourced directly from the ASPECT-NP trial. Estimates of clinical effectiveness for other relevant comparators included within the economic model were searched via systematic review. However, due to the presence of heterogeneity and violations of the assumptions required to conduct scientifically robust network-meta analysis; the efficacy and mortality of these intervention were assumed to be the same as ceftolozane/tazobactam.

\section{Susceptibility}

Pathogen-specific susceptibility data from the US sample $(n=2333)$ of the PACTS database 2011-2018 were used to determine the proportion of patients whose infections were susceptible (and not susceptible) to early treatment (Fig. 1a), and to calculate the proportion of patients receiving subsequent treatment(s). Details of the PACTS analysis are provided in Appendix A1.

\section{Efficacy}

Clinical response and all-cause mortality rates for ceftolozane/tazobactam and meropenem were informed by the microbiological intent-totreat (mITT) population of ASPECT-NP [21]. The mITT population consisted of all patients in the 
Table 1 Key clinical inputs

\begin{tabular}{|c|c|c|c|}
\hline Category & Input & Value & References \\
\hline \multicolumn{4}{|l|}{ Efficacy } \\
\hline \multirow[t]{8}{*}{ Response rate } & Ceftolozane/tazobactam & $60.61 \%$ & ASPECT-NP mITT population [35] \\
\hline & $\begin{array}{l}\text { Subsequent line treatment } \\
\text { (following } \\
\text { ceftolozane/tazobactam) }\end{array}$ & $60.61 \%$ & Assumed equal to ceftolozane/tazobactam \\
\hline & $\begin{array}{l}\text { De-escalation treatment } \\
\text { (following } \\
\text { ceftolozane/tazobactam) }\end{array}$ & $60.61 \%$ & \\
\hline & $\begin{array}{l}\text { Switch treatment (following } \\
\text { ceftolozane/tazobactam) }\end{array}$ & $28.04 \%$ & ASPECT-NP [35], adjusted using Raman et al. [13] \\
\hline & Meropenem & $56.68 \%$ & ASPECT-NP mITT population [35] \\
\hline & $\begin{array}{l}\text { Second-line treatment (following } \\
\text { meropenem) }\end{array}$ & $60.61 \%$ & Assumed equal to ceftolozane/tazobactam \\
\hline & $\begin{array}{l}\text { De-escalation treatment } \\
\quad(\text { following meropenem })\end{array}$ & $56.68 \%$ & Assumed equal to meropenem \\
\hline & $\begin{array}{l}\text { Switch treatment (following } \\
\text { meropenem) }\end{array}$ & $25.29 \%$ & ASPECT-NP [35], adjusted using Raman et al. [13] \\
\hline \multirow[t]{8}{*}{ Mortality rate } & Ceftolozane/tazobactam & $20.08 \%$ & ASPECT-NP [35] \\
\hline & $\begin{array}{l}\text { Second-line treatment (following } \\
\text { ceftolozane/tazobactam) }\end{array}$ & $20.08 \%$ & Assumed equal to ceftolozane/tazobactam \\
\hline & $\begin{array}{l}\text { De-escalation treatment } \\
\text { (following } \\
\text { ceftolozane/tazobactam) }\end{array}$ & $20.08 \%$ & \\
\hline & $\begin{array}{l}\text { Switch treatment (following } \\
\text { ceftolozane/tazobactam) }\end{array}$ & $42.24 \%$ & ASPECT-NP [35], adjusted using Siempos et al. [14] \\
\hline & Meropenem & $25.51 \%$ & ASPECT-NP [35] \\
\hline & $\begin{array}{l}\text { Second-line treatment (following } \\
\text { meropenem) }\end{array}$ & $20.08 \%$ & Assumed equal to ceftolozane/tazobactam \\
\hline & $\begin{array}{l}\text { De-escalation treatment } \\
\quad(\text { following meropenem) }\end{array}$ & $25.51 \%$ & Assumed equal to meropenem \\
\hline & $\begin{array}{l}\text { Switch treatment (following } \\
\text { meropenem) }\end{array}$ & $42.31 \%$ & ASPECT-NP [35], adjusted using Siempos et al. [14] \\
\hline \multicolumn{4}{|c|}{ Pathogen type and susceptibility } \\
\hline \multirow{4}{*}{$\begin{array}{l}\text { Distribution of major } \\
\text { pathogens }\end{array}$} & Acinetobacter & $28.6 \%$ & US-specific PACTS 2011-2018 [37] \\
\hline & Enterobacteriaceae & $46.8 \%$ & \\
\hline & Haemophilus & $0.2 \%$ & \\
\hline & Pseudomonas & $24.4 \%$ & \\
\hline
\end{tabular}


Table 1 continued

\begin{tabular}{|c|c|c|c|}
\hline Category & Input & Value & References \\
\hline \multirow[t]{2}{*}{ Susceptibility } & $\begin{array}{l}\text { Proportion susceptible to early } \\
\text { treatment of } \\
\text { ceftolozane/tazobactam }\end{array}$ & $83.69 \%$ & \multirow[t]{3}{*}{$\begin{array}{l}\text { US-specific PACTS 2011-2018 [37]; weighted by } \\
\text { pathogen percentages }\end{array}$} \\
\hline & $\begin{array}{l}\text { Proportion susceptible to early } \\
\text { treatment of meropenem }\end{array}$ & $78.87 \%$ & \\
\hline \multicolumn{3}{|l|}{ In-hospital LOS (days) } & \\
\hline \multirow{6}{*}{$\begin{array}{l}\text { LOS on mechanical } \\
\text { ventilation }\end{array}$} & Cured_ceftolozane/tazobactam & 16.28 & \multirow[t]{18}{*}{ mITT population in ASPECT-NP [35] } \\
\hline & $\begin{array}{l}\text { Not cured- } \\
\text { ceftolozane/tazobactam }\end{array}$ & 23.95 & \\
\hline & Death-ceftolozane/tazobactam & 11.58 & \\
\hline & Cured-meropenem & 17.24 & \\
\hline & Not cured-meropenem & 24.03 & \\
\hline & Death-meropenem & 11.63 & \\
\hline \multirow{6}{*}{$\begin{array}{l}\text { ICU LOS (including } \\
\text { ventilated ICU stay) }\end{array}$} & Cured-ceftolozane/tazobactam & 2.08 & \\
\hline & $\begin{array}{l}\text { Not cured- } \\
\text { ceftolozane/tazobactam }\end{array}$ & 0.00 & \\
\hline & Death_ceftolozane/tazobactam & 0.58 & \\
\hline & Cured-meropenem & 2.22 & \\
\hline & Not cured-meropenem & 0.29 & \\
\hline & Death-meropenem & 1.16 & \\
\hline \multirow{6}{*}{$\begin{array}{l}\text { General ward LOS } \\
\text { (following ICU) }\end{array}$} & Cured-ceftolozane/tazobactam & 11.34 & \\
\hline & $\begin{array}{l}\text { Not cured- } \\
\text { ceftolozane/tazobactam }\end{array}$ & 8.84 & \\
\hline & Death-ceftolozane/tazobactam & 1.16 & \\
\hline & Cured-meropenem & 9.44 & \\
\hline & Not cured-meropenem & 5.99 & \\
\hline & Death-meropenem & 0.53 & \\
\hline \multirow{3}{*}{$\begin{array}{l}\text { Resource associated with } \\
\text { subsequent treatment }\end{array}$} & Additional ventilator LOS & 3.41 & \multirow{6}{*}{$\begin{array}{l}\text { Zilberberg et al. (2017) [23], re-distributed among settings } \\
\text { proportional to ASPECT-NP average LOS in each } \\
\text { setting }\end{array}$} \\
\hline & Additional ICU LOS & 0.27 & \\
\hline & Additional general ward LOS & 1.52 & \\
\hline \multirow{3}{*}{$\begin{array}{l}\text { Resource associated with } \\
\text { early inappropriate } \\
\text { therapy }\end{array}$} & Additional ventilator LOS & 3.41 & \\
\hline & Additional ICU LOS & 0.27 & \\
\hline & Additional general ward LOS & 1.52 & \\
\hline Costs $(2019 \$)$ & & & \\
\hline
\end{tabular}


Table 1 continued

\begin{tabular}{|c|c|c|c|}
\hline Category & Input & Value & References \\
\hline \multirow[t]{8}{*}{ Daily drug cost } & Ceftolozane/tazobactam ${ }^{\mathrm{a}}$ & $\$ 751.32$ & 2019 US WAC price [24] \\
\hline & $\begin{array}{l}\text { Second-line treatment (following } \\
\text { ceftolozane/tazobactam) }\end{array}$ & $\$ 18.44$ & \\
\hline & $\begin{array}{l}\text { De-escalation treatment } \\
\text { (following } \\
\text { ceftolozane/tazobactam) }\end{array}$ & $\$ 61.35$ & \\
\hline & $\begin{array}{l}\text { Switch treatment (following } \\
\text { ceftolozane/tazobactam) }\end{array}$ & $\$ 45.47$ & \\
\hline & Meropenem & $\$ 69.45$ & \\
\hline & $\begin{array}{l}\text { Second-line treatment (following } \\
\text { meropenem) }\end{array}$ & $\$ 19.48$ & \\
\hline & $\begin{array}{l}\text { De-escalation treatment } \\
\quad(\text { following meropenem) }\end{array}$ & $\$ 63.85$ & \\
\hline & $\begin{array}{l}\text { Switch treatment (following } \\
\text { meropenem) }\end{array}$ & $\$ 40.91$ & \\
\hline \multirow{3}{*}{$\begin{array}{l}\text { Hospital resource, per } \\
\text { day }\end{array}$} & Mechanical ventilation & $\$ 6825.44$ & Wunsch et al. (2010) [27] \\
\hline & ICU stay (post-ventilation) & $\$ 5485.87$ & Halpern et al. (2010) [26] \\
\hline & Hospital stay (post-ICU) & $\$ 2395.92$ & Becker's Healthcare (2013) [25] \\
\hline \multirow{8}{*}{$\begin{array}{l}\text { Adverse event cost, per } \\
\text { treated patient }\end{array}$} & Ceftolozane/tazobactam & $\$ 5035.71$ & AHRQ HCUP [29] \\
\hline & $\begin{array}{l}\text { Second-line treatment (following } \\
\text { ceftolozane/tazobactam) }\end{array}$ & $\$ 4394.26$ & \\
\hline & $\begin{array}{l}\text { De-escalation treatment } \\
\text { (following } \\
\text { ceftolozane/tazobactam) }\end{array}$ & $\$ 4404.88$ & \\
\hline & $\begin{array}{l}\text { Switch treatment (following } \\
\text { ceftolozane/tazobactam) }\end{array}$ & $\$ 7393.15$ & \\
\hline & Meropenem & $\$ 4791.83$ & \\
\hline & $\begin{array}{l}\text { Second-line treatment (following } \\
\text { meropenem) }\end{array}$ & $\$ 3757.06$ & \\
\hline & $\begin{array}{l}\text { De-escalation treatment } \\
\quad \text { (following meropenem) }\end{array}$ & $\$ 3207.86$ & \\
\hline & $\begin{array}{l}\text { Switch treatment (following } \\
\text { meropenem) }\end{array}$ & $\$ 7043.91$ & \\
\hline \multicolumn{4}{|l|}{ Utilities } \\
\hline \multirow[t]{2}{*}{ Utility value by setting } & Patients treated in ICU & 0.68 & Whittington et al. (2017) [31] \\
\hline & Patients treated in general ward & 0.73 & Lee et al. (2010) [32] \\
\hline
\end{tabular}

$I C U$ intensive care unit, $L O S$ length of stay

a Based on the price of $\$ 125.22$ per vial for $1 \mathrm{~g} / 5 \mathrm{mg}$ ceftolozane/tazobactam, daily cost is calculated by $2 \mathrm{~g} / 1 \mathrm{~g}$ dose per administration every 8 h: $\$ 125.22 \times 2 \times 3=\$ 751.32$ per day. See Appendix A3 for more details 
ITT population except those who had only a Gram-positive causative pathogen, or who were resistant to either of the study drugs, or did not receive any amount of a study drug. As efficacy data are applied in the model to patients who receive a drug with confirmed susceptibility, the mITT population is believed more relevant than the ITT population.

A systematic literature review (SLR) was conducted to identify relevant data to support the determination of comparative clinical effectiveness of antimicrobials versus ceftolozane/tazobactam. Results of the SLR were limited and presented a number of challenges, including, but not limited to, variation in study design, outcome definition, assessment timepoint, geography, and baseline pathogen. Given this variation, and the vast time span of the evidence ( 2 decades) there was a concern relating to the relevance of these data when considering evolving epidemiology, and the evolution of HABP/VABP definition and management.

A network meta-analysis was considered; however, due to the variability and violation of key assumptions (homogeneity and similarity), the decision was made to assume no difference. This decision was considered to be conservative, and an attempt to reflect the outcome of noninferiority observed within each original study, as required by regulators. That is, clinical effectiveness (cure rate and mortality) values for all subsequent treatment options were considered the same as ceftolozane/tazobactam, akin to an odds ratio (OR) of 1.0.

It has been widely documented that HABP/ VABP patients receiving initial inappropriate antibiotic treatment have higher mortality and lower cure rate $[13,14,22]$. Therefore efficacy penalties were applied to patients that switched treatment after receiving first-line inappropriate therapy, including a lower clinical cure rate (OR 0.22 , [13]), and increased mortality (OR 2.92, [14]).

\section{In-hospital Length of Stay}

Using data from the mITT population (ASPECT$\mathrm{NP})$ the average duration of three types of hospital resource use were included in the model. These LOS inputs were considered sequentially, following patient entry through to cure within the model (1) being admitted to ICU with mechanical ventilation, (2) remaining in the ICU without ventilation, (3) moving to a general ward.

In addition to the average LOS observed in ASPECT-NP, a LOS penalty of 5.2 days [23] was applied to patients who received early inappropriate therapy or who failed first-line treatment and received a subsequent line of treatment. The penalty reflect the study that reported an increase in total hospital LOS due to early inappropriate therapy among patients with urinary tract infection, pneumonia, or sepsis due to Enterobacterales [23]. However, the distribution of the additional LOS among the three aforementioned healthcare resource types are not reported. We assumed that the additional ventilator usage and general ward stay is proportional to the average LOS for each setting observed in ASPECT-NP. With this assumption, the additional 5.2 days are redistributed among the three resource types.

\section{Adverse Events}

Adverse events (AEs) associated with ceftolozane/tazobactam and meropenem were sourced from ASPECT-NP and included if they were (1) treatment-related and occurred in $\geq 5 \%$ of patients, or (2) treatment-related and serious. In addition to those described nephrotoxicity, though absent in the ASPECT-NP, was included due to potential renal toxicity associated with colistin and aminoglycosides as subsequent line options. Unadjusted AE data were sourced from the relevant clinical trials (see Appendix A2).

\section{Costs}

Total drug costs were calculated using observed ASPECT-NP treatment duration data, dosing regimens, and dose-specific per pack US 2019 wholesale acquisition cost [24]. The same treatment duration is applied across treatment outcomes (cured, uncured, or death). Weighted daily drug costs by treatment setting (first and subsequent lines of treatment, de-escalation, or 
switch) are provided in Table 1 (more details in Appendix A3).

Hospitalisation costs, including the daily cost of the three resource types, were sourced from the literature [25-27]. Long-term monitoring costs, following initial discharge, included a monthly outpatient visit (CPT 99213) [28] for $80 \%$ of cured patients for 1 year. AE-related costs were based on the 2016 Healthcare Cost and Utilisation Project data [29]. All costs were inflated to 2018/2019 dollars using the medical care consumer price index [30].

\section{Health-Related Quality of Life}

Utility values were applied to patients according to their health state (cured or uncured) and hospital setting (ICU [31] and general ward [32]). Disutility values associated with AEs were sourced from the literature. The average QALY loss per AE incidence was calculated by multiplying AE disutility by the average AE duration [29]. The model assumed that the health-related quality of life of cured patients returns to that of the general population once they are cured; this is based on gender and age category estimate [33].

\section{Analysis}

Outcomes included: (1) the percentage of patients cured and dead during the initial hospitalisation, (2) total healthcare costs (including drug acquisition, hospital resource use, longterm monitoring, and AEs), (3) life-years and QALYs, and (4) incremental cost-effectiveness ratio (ICER) calculated as the difference in lifetime costs per QALY gained.

Several sensitivity analyses were carried out. First, one-way sensitivity analysis (OWSA) was conducted by varying individual model input parameters in turn to its upper and lower bounds (calculated from the 95\% confidence interval of the assigned probability distribution) to identify key drivers of the ICER. Second, in probabilistic sensitivity analysis (PSA), all parameters subject to uncertainty were simultaneously randomly sampled from their assigned probability distributions for 10,000 iterations. Values of input parameters tested in the OWSA and PSA are listed in Appendix A4. Third, scenario analyses were conducted to explore structural uncertainty (see Appendix A5). Scenario analyses tested infection sitespecific subgroups (ventilated HABP alone and VABP alone), alternative ASPECT-NP efficacy data (clinically evaluable [CE] and ITT cohort data), as well as assumptions of the LOS penalty for early inappropriate therapy and uncured patients. Lastly, this study was based on previously conducted studies and does not contain any new studies with human participants or animals performed by any of the authors.

\section{RESULTS}

\section{Base Case}

Summarised in Table 2 are model results from both treatment settings. In the confirmed setting use, ceftolozane/tazobactam achieved a higher overall cure rate $(72.3 \%$ vs. $67.5 \%$, including cure by subsequent line of treatment) and a lower 1-year mortality rate $(27.7 \%$ vs. $32.5 \%)$ vs. meropenem. Hospitalisation costs were marginally higher for ceftolozane/tazobactam, largely due to the increased number of patients alive requiring resources. However, on average patients treated with ceftolozane/tazobactam spent less time mechanically ventilated (16.1 vs. 16.5 days) compared with meropenem-treated patients. Over the lifetime horizon, ceftolozane/tazobactam incurred incremental costs of $\$ 7247$ and generates 0.60 additional QALYs compared to meropenem. The corresponding ICER of $\$ 12,126$ per QALY gained is substantially below the US WTP thresholds of $\$ 50,000$ and $\$ 150,000$ typically used by the Institute for Clinical and Economic Research [19], indicating that ceftolozane/tazobactam may be considered a cost-effective treatment option in the confirmed treatment setting.

In the early treatment setting, when compared with meropenem, ceftolozane/tazobactam achieved a higher proportion of patients cured $(62.7 \%$ vs. $53.9 \%)$, had a lower 1-year mortality rate $(25.9 \%$ vs. $32.3 \%)$, and reduced 
Table 2 Base case results

\section{Ceftolozane/tazobactam}

Meropenem

Confirmed setting: among ventilated HABP/VABP patients with confirmed susceptibility to ceftolozane/tazobactam or meropenem

Efficacy

Early treatment cure rate ${ }^{a}$

$60.61 \%$

$56.68 \%$

Early treatment mortality rate ${ }^{a}$

$20.08 \%$

$25.51 \%$

Overall cure rate

$72.32 \%$

$67.48 \%$

Overall mortality rate ${ }^{\mathrm{b}}$

$27.68 \%$

$32.52 \%$

Resource use

Mechanical ventilation days

16.10

16.45

ICU days (no ventilation)

1.70

1.89

General ward days (following ICU)

9.10

7.00

Total hospital LOS

26.90

25.35

Costs

Treatment costs

$\$ 6051$

$\$ 547$

Hospital resource costs

$\$ 140,994$

$\$ 139,438$

AE costs

$\$ 5673$

$\$ 5514$

Monitoring costs (long-term)

$\$ 464$

$\$ 436$

Total costs

$\$ 153,182$

$\$ 145,935$

Outcomes

Life years-total

10.89

10.16

QALYS-total

8.93

8.33

Incremental analysis $(\Delta C / T$-meropenem $)$

Incremental costs

$\$ 7247$

Incremental QALYs

0.60

ICER

$\$ 12,126$

Early treatment setting: among ventilated HABP/VABP patients

Efficacy

First-line cure rate ${ }^{\mathrm{a}}$

$40.58 \%$

$35.76 \%$

First-line mortality rate ${ }^{\mathrm{a}}$

$12.93 \%$

$11.24 \%$

Overall cure rate

$62.69 \%$

$53.85 \%$

Overall mortality rate ${ }^{b}$

$37.31 \%$

$43.15 \%$

Resource use

Mechanical ventilation days

17.44

18.11 
Table 2 continued

\begin{tabular}{lll}
\hline & Ceftolozane/tazobactam & Meropenem \\
\hline ICU days (no ventilation) & 1.58 & 1.80 \\
General ward days (following ICU) & 9.08 & 7.06 \\
Total hospital LOS & 28.11 & 26.97 \\
Costs & & \\
Treatment costs & $\$ 4177$ & $\$ 360$ \\
Hospital resource costs & $\$ 149,476$ & $\$ 150,417$ \\
AE costs & $\$ 7888$ & $\$ 8140$ \\
Monitoring costs (long-term) & $\$ 420$ & $\$ 389$ \\
Total costs & $\$ 161,961$ & $\$ 158,546$ \\
Outcomes & & \\
Life years & 9.84 & 8.60 \\
QALYs & 7.78 & 7.06 \\
Incremental analysis & & \\
Incremental costs & $\$ 3415$ & \\
Incremental QALYs & 0.72 & \\
ICER & $\$ 4775$ & \\
\hline
\end{tabular}

Totals may not sum exactly due to rounding

$A E$ adverse event, ICER incremental cost-effectiveness ratio, ICU intensive care unit, LOS length of stay, QALYs qualityadjusted life-years

a Mortality and clinical cure rates are based on the mITT cohort data from the ASPECT-NP trial

b Overall mortality was based on the assumption that, given severity of ventilated HABP/VABP, uncured patients would die within 1 year

the average LOS for patients in receipt of mechanic ventilation (17.4 vs. 18.1 days). The higher treatment cost of ceftolozane/tazobactam versus meropenem was partially offset by savings from hospital resource use, resulting in a total incremental cost of $\$ 3,415$. Furthermore, ceftolozane/tazobactam generated more lifetime QALYs than meropenem (0.72 increment). Consistent with the findings in the confirmed treatment setting, the ICER in the early treatment setting was $\$ 4775$ per QALY gained. This suggests that ceftolozane/tazobactam may have the potential to be even more cost-effective when used in the early treatment compared with the confirmed treatment.

\section{Sensitivity Analysis}

The OWSA results (Fig. 2) indicate that, in both the early and confirmed treatment settings, the most influential parameters are the numbers of days spent on: mechanical ventilation, the ICU ward, and the general ward. This was expected given that hospital LOS directly affects resource use costs in the short-term model, where most costs are incurred.

The cost-effectiveness acceptability curves from PSA (Fig. 3) show the likelihood that each treatment is a cost-effective option at various WTP thresholds (calculated based on the outcomes of each PSA iteration). In the both 


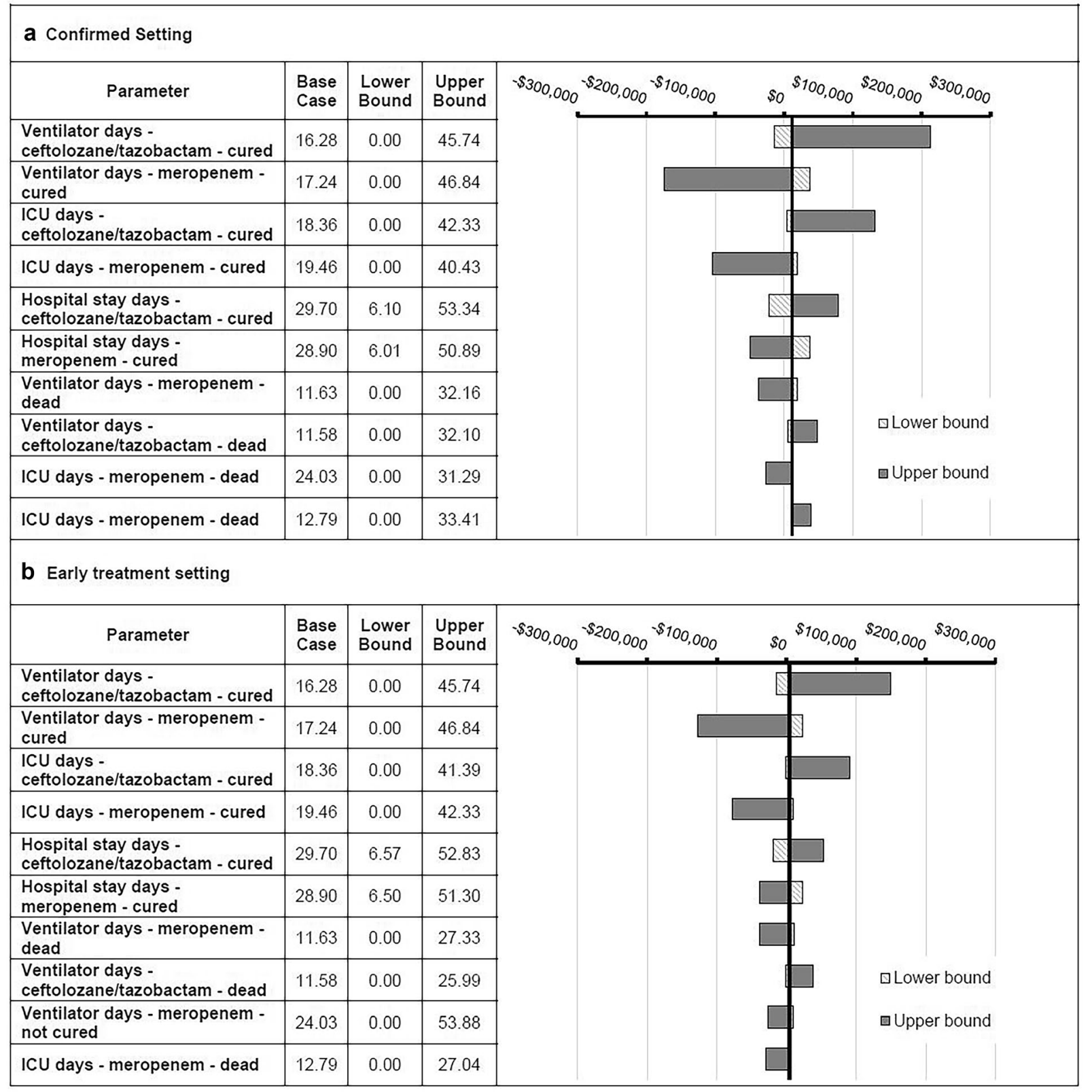

Fig. 2 OWSA-Tornado diagrams-ceftolozane/tazobactam versus meropenem-ICERs. ICU intensive care unit

treatment settings, within the WTP range of $\$ 50,000-\$ 150,000$ (per QALY gained), ceftolozane/tazobactam is considered substantially more likely to be the cost-effective treatment option compared with meropenem. The cost effectiveness of ceftolozane/tazobactam versus meropenem was maintained in scenario analyses for a number structural model changes (results presented in Appendix A5). However, ceftolozane/tazobactam was not shown to be cost-effective in the confirmed treatment setting among a subgroup of patients with VABP.

\section{DISCUSSION}

Due to increasing levels of resistance and an over reliance of standard-of-care regimens, 

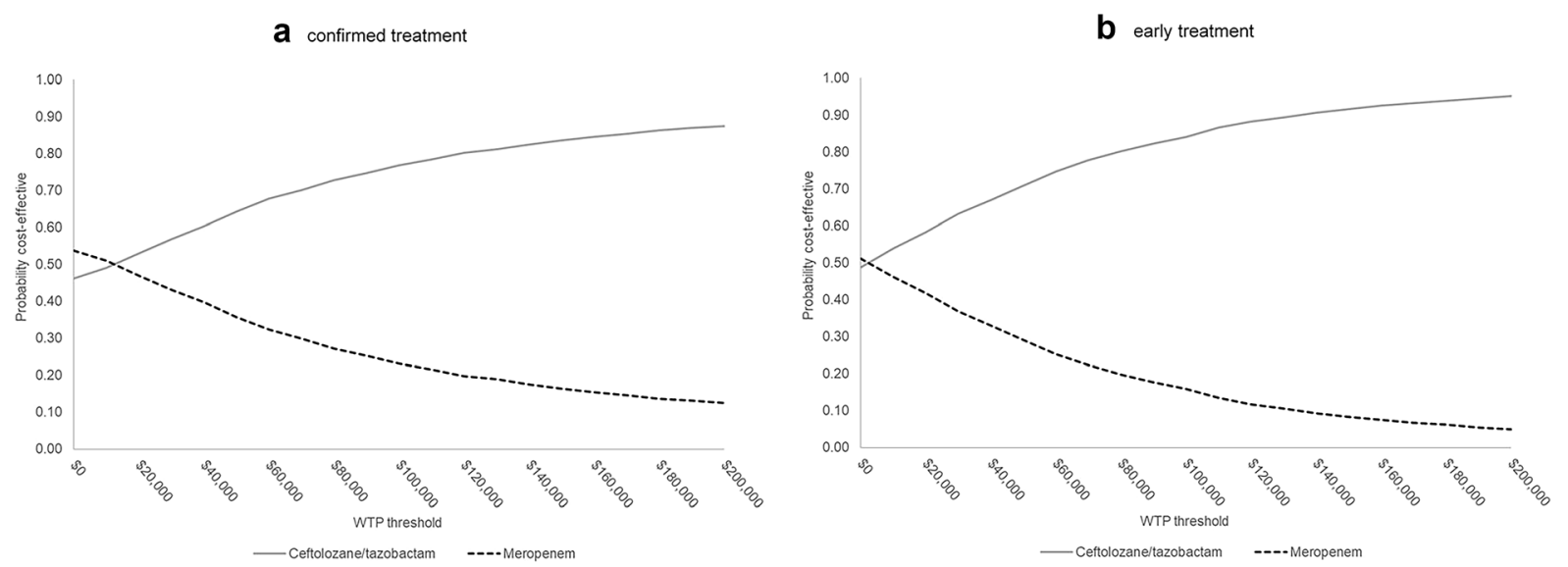

Fig. 3 Cost-effectiveness acceptability curves. WTP willingness-to-pay

Gram-negative bacterial infections are recognised as a global threat. HABP/VABP patients are often critically ill and benefit from appropriate early treatment. The acquisition cost of novel antimicrobials is often higher the standard-ofcare. However, it is important to evaluate the overall cost of managing an infection before making judgements of value. This is the first study to examine the cost-effectiveness of ceftolozane/tazobactam for the treatment of ventilated $\mathrm{vHABP} / \mathrm{VABP}$. In addition to efficacy data derived from the ASPECT NP phase III trial, this study also incorporated real-world estimates of susceptibility and antimicrobial treatment management; including subsequent lines of therapy or salvage treatment, following firstline treatment failure.

Our model examined two real-world scenarios for the use of ceftolozane/tazobactam in the early treatment of high-risk patients before their susceptibility profile is known, and the confirmed treatment for patients with confirmed susceptibility. Findings from both treatment settings were consistent, indicating that ceftolozane/tazobactam, compared to meropenem, cures more patients, reduces shortterm mortality, and reduces the average LOS in the ICU and the duration of mechanical ventilation. These benefits, despite increased drug costs, demonstrate that ceftolozane/tazobactam has the potential to be cost-effective in both treatment settings.
Ventilated HABP and VABP are associated with a high mortality rate and heavy healthcare resource needs. Our study suggests that treatment with ceftolozane/tazobactam among patients with confirmed susceptibility could benefit from a reduction in the mortality rate by $15 \%$ (or $27.7-32.5 \%=-4.8$ absolute percentage points), compared to meropenem, with almost unchanged hospital resource needs per patient (confirmed setting: \$140,994 ceftolozane/tazobactam vs. $\$ 139,438$ meropenem, or $1.1 \%$ difference; early setting: $\$ 149,476$ ceftolozane/tazobactam vs. $\$ 150,417$ meropenem, or $-0.6 \%$ difference). This result suggests that ceftolozane/tazobactam could potentially achieve better health outcomes without unduly adding to the heavy economic burden of HABP/VABP treatment in the US [34].

While ceftolozane/tazobactam is a cost-effective treatment option in the confirmed treatment setting, our model also suggests that there could be additional health benefits from utilising ceftolozane/tazobactam earlier in the treatment $(4.8 \%$ less mortality in the confirmed setting vs. $5.8 \%$ in early treatment). This is because ceftolozane/tazobactam has the potential to reduce the proportion of patients experiencing a poor clinical response, higher mortality, and longer in-hospital LOS as a result of inappropriate or resistant initial therapies, due to its broader susceptibility profile $(83.7 \%$ susceptible) compared with meropenem (78.9\%). In addition, the susceptibility data was 
derived from the US cohort of ICU-admitted respiratory infection patients, instead of the selective sample at a high risk of carbapenem resistance. Therefore, the susceptibility difference may not reflect that in the patients with suspected resistance to existing treatment options that ceftolozane/tazobactam targets. Therefore, it is reasonable to expect that realworld early treatment use of ceftolozane/tazobactam could generate health and economic benefits to a larger extent than demonstrated in this study.

As with all HCRU studies, several limitations are present. To begin with, the demographic, safety, and efficacy data were taken directly from the ASPECT-NP trial population, which is comprised of severely ill patients that are 100\% ventilated [35]; therefore, the results may not be generalisable to HABP/VABP patients overall, especially non-ventilated HABP patients included in the labelled indication. Secondly, the susceptibility data, derived from a US sub-sample of a global surveillance database, may not fully align with local hospital epidemiology; which has been shown to play a major role in selection and outcome of antimicrobial therapy based on pathogen distribution and resistance profiles. Thirdly, the model assumes that patients who are alive but not cured die within a year. In clinical practice, additional lines of therapy and combination therapy could be added to patients' therapeutic regimen. Lastly, our assessment of cost-effectiveness of ceftolozane/tazobactam is limited to direct benefits borne by treated patients. This study does not consider the potential additional value of ceftolozane/tazobactam as a novel agent, i.e. the ability to slow the development of resistance, reduce the spread of infection, and the enablement of antibiotic sparing and diversification of prescribing patterns [36].

\section{CONCLUSIONS}

The results of this analysis indicate that ceftolozane/tazobactam when used in either the early or confirmed treatment setting for patients with vHABP/HABP is a cost-effective option in the US. This finding when considered in the context of good antimicrobial stewardship should prove valuable to decision-makers and clinicians when selecting an appropriate antimicrobial therapy for patients who present with vHABP/VABP.

\section{ACKNOWLEDGEMENTS}

Funding. Funding for this research was provided by Merck Sharp \& Dohme Corp., a subsidiary of Merck \& Co., Inc., Kenilworth, New Jersey, USA (MSD). MSD provided funding for the journal's Rapid Service Fee.

Authorship. All named authors meet the International Committee of Medical Journal Editors (ICMJE) criteria for authorship for this article, take responsibility for the integrity of the work as a whole, and have given their approval for this version to be published.

Authors' Contribution. All authors are responsible for the work described in this paper. All authors were involved in at least one of the following: [conception, design of work or acquisition, analysis, interpretation of data] and [drafting the manuscript and/or revising/reviewing the manuscript for important intellectual content]. All authors provided final approval of the version to be published. All authors agree to be accountable for all aspects of the work in ensuring that questions related to the accuracy or integrity of any part of the work are appropriately investigated and resolved.

Prior Presentation. This work was presented, in part, at the Infectious Diseases Society of America (IDSA) ID Week 2019 during October 2-6, 2019 in Washington, DC, USA. All accepted abstracts were posted in the 2019 ID Week abstract book.

Disclosures. Jaesh Naik, Simone Critchlow, and David Elsea are employees of Bresmed, which received a collaborative contract from Merck \& Co., Inc., Kenilworth, NJ, USA. Joe Yang, Ryan Dillon, and Laura Puzniak are employees of Merck Sharp \& Dohme Corp., a 
subsidiary of Merck \& Co., Inc., Kenilworth, NJ, USA (MSD) and may own stock and/or hold stock options in Merck \& Co., Inc., Kenilworth, NJ, USA.

Compliance with Ethics Guidelines. This article is based on previously conducted studies and does not contain any new studies with human participants or animals performed by any of the authors.

Data Availability. Data Availability. Merck Sharp \& Dohme Corp., a subsidiary of Merck \& Co., Inc., Kenilworth, NJ, USA's data sharing policy, including restrictions, is available at http://engagezone.msd.com/ds_documentation. php. Requests for access to tPrior Presentationhe clinical study data can be submitted through the EngageZone site or via email to dataaccess@merck.com.

Open Access. This article is licensed under a Creative Commons Attribution-NonCommercial 4.0 International License, which permits any non-commercial use, sharing, adaptation, distribution and reproduction in any medium or format, as long as you give appropriate credit to the original author(s) and the source, provide a link to the Creative Commons licence, and indicate if changes were made. The images or other third party material in this article are included in the article's Creative Commons licence, unless indicated otherwise in a credit line to the material. If material is not included in the article's Creative Commons licence and your intended use is not permitted by statutory regulation or exceeds the permitted use, you will need to obtain permission directly from the copyright holder. To view a copy of this licence, visit http:// creativecommons.org/licenses/by-nc/4.0/.

\section{REFERENCES}

1. Karalliedde LD, et al. Adverse drug interactions: a handbook for prescribers. Boca Raton: CRC; 2016.

2. US Department of Health and Human ServicesFood and Drug Administration. Hospital-Acquired
Bacterial Pneumonia and Ventilator-Associated Bacterial Pneumonia: Developing Drugs for Treatment 201424 July 2019. https://www.fda.gov/ regulatory-information/search-fda-guidance-docu ments/hospital-acquired-bacterial-pneumonia-andventilator-associated-bacterial-pneumonia-develop ing-drugs.

3. Hunter JD. Ventilator associated pneumonia. BMJ Br Med J. 2012;344:e3325.

4. Talbot $\mathrm{GH}$, et al. Evidence-based study design for hospital-acquired bacterial pneumonia and ventilator-associated bacterial pneumonia. J Infect Dis. 2019;219(10):1536-44.

5. Sader HS, et al. Antimicrobial susceptibility of Gram-negative organisms isolated from patients hospitalised with pneumonia in US and European hospitals: results from the SENTRY Antimicrobial Surveillance Program, 2009-2012. Int J Antimicrob Agents. 2014;43(4):328-34.

6. Kalil AC, et al. Management of adults with hospitalacquired and ventilator-associated pneumonia: 2016 Clinical Practice Guidelines by the Infectious Diseases Society of America and the American Thoracic Society. Clin Infect Dis. 2016;63(5): e61-111.

7. Weiss E, et al. Treatment of severe hospital-acquired and ventilator-associated pneumonia: a systematic review of inclusion and judgment criteria used in randomized controlled trials. Crit Care. 2017;21:1.

8. World Health Organization. Global priority list of antibiotic-resistant bacteria to guide research, discovery, and development of new antibiotics. Geneva: WHO; 2017.

9. Morata L, et al. Influence of multidrug resistance and appropriate empirical therapy on the 30-day mortality rate of Pseudomonas aeruginosa bacteremia. Antimicrob Agents Chemother. 2012;56(9):4833-7.

10. Merchant S, et al. Risk factors for Pseudomonas aeruginosa infections in Asia-Pacific and consequences of inappropriate initial antimicrobial therapy: a systematic literature review and metaanalysis. J Glob Antimicrob Resist. 2018;14:33-44.

11. Rello J. Importance of appropriate initial antibiotic therapy and de-escalation in the treatment of nosocomial pneumonia. Eur Respir Rev. 2007;16(103):33.

12. Khan RA, Bakry MM, Islahudin F. Appropriate antibiotic administration in critically ill patients with pneumonia. Indian J Pharm Sci. 2015;77(3): 299-305. 
13. Raman G, et al. Appropriate initial antibiotic therapy in hospitalized patients with Gram-negative infections: systematic review and meta-analysis. BMC Infect Dis. 2015;15:395.

14. Siempos II, et al. Predictors of mortality in adult patients with ventilator-associated pneumonia: a meta-analysis. Shock. 2010;33(6):590-601.

15. Merck \& Co., I., Kenilworth, NJ, USA,, Data on file: ASPECT-NP Clinical Study Report 2018.

16. JMI Laboratories. Ceftolozane-tazobactam 2018 surveillance for the United States. 2018.

17. Merck \& Co. Inc., K., NJ, USA, Ceftolozane/tazobactam (ZERBAXA ${ }^{\circledR}$ ) [Prescribing information]. Whitehouse, NJ. 2019.

18. Merck \& Co. Inc., K., NJ, USA, IMI/REL model specification validation interviews. 2017 .

19. Institute for Clinical and Economic Review. ICER's Reference Case for Economic evaluations: principles and rationale. 201816 July 201821 May 2019. https://icer-review.org/wp-content/uploads/2018/ 07/ICER_Reference_Case_July-2018.pdf.

20. Shortridge D, et al. Antimicrobial activity of ceftolozane-tazobactam tested against Enterobacteriaceae and Pseudomonas aeruginosa with various resistance patterns isolated in US hospitals (2013-2016) as part of the surveillance program: program to assess ceftolozane-tazobactam susceptibility. Microb Drug Resist. 2018;24(5):563-77.

21. Kollef $\mathrm{MH}$, et al. Ceftolozane-tazobactam versus meropenem for treatment of nosocomial pneumonia (ASPECT-NP): a randomised, controlled, double-blind, phase 3, non-inferiority trial. Lancet Infect Dis. 2019;19(12):1299-311.

22. Dupont $\mathrm{H}$, et al. Impact of appropriateness of initial antibiotic therapy on the outcome of ventilatorassociated pneumonia. Intensive Care Med. 2001;27(2):355-62.

23. Zilberberg MD, et al. Carbapenem resistance, inappropriate empiric treatment and outcomes among patients hospitalized with Enterobacteriaceae urinary tract infection, pneumonia and sepsis. BMC Infect Dis. 2017;17(1):279.

24. Analysource. 2019 Wholesale acquisition cost database. 2019.

25. Becker's Healthcare. Average cost per inpatient day across 50 states. 2015, 21 May 2019. https://www. beckershospitalreview.com/finance/average-costper-inpatient-day-across-50-states.html.
26. Halpern NA, Pastores SM. Critical care medicine beds, use, occupancy, and costs in the United States: a methodological review. Crit Care Med. 2015;43(11):2452-9.

27. Wunsch $\mathrm{H}$, et al. The epidemiology of mechanical ventilation use in the United States. Crit Care Med. 2010;38(10):1947-53.

28. Centers for Medicare and Medicaid Services. Physician Fee Schedule. 2019, 04 May 2019. https:// www.cms.gov/apps/physician-fee-schedule/over view.aspx.

29. Agency for Healthcare Research and Quality. HCUPnet Healthcare Cost and Utilization Project. 2016, 21 May 2019. https://hcupnet.ahrq.gov/ \#setup.

30. Statistics, U.S.B.o.L. Measuring price change in the CPI: Medical care. 2020.

31. Whittington $\mathrm{MD}$, et al. Recommendations for methicillin-resistant Staphylococcus aureus prevention in adult ICUs: a cost-effectiveness analysis. Crit Care Med. 2017;45(8):1304-10.

32. Lee BY, et al. The economic effect of screening orthopedic surgery patients preoperatively for methicillin-resistant Staphylococcus aureus. Infect Control Hosp Epidemiol. 2010;31(11):1130-8.

33. World Health Organization. Antimicrobial Resistance Global Report on Surveillance. 2014 June 20147 September 2018. http://apps.who.int/iris/ bitstream/handle/10665/112642/9789241564748_ eng.pdf; jsessionid=97E35610C6A73606BC924B22 3F67F85D?s equence $=1$.

34. Sun D, et al. Economic burden of ventilator-associated, hospital-acquired, healthcare-associated and community-acquired pneumonia in the hospital setting. In Open Forum Infectious Diseases. Oxford: Oxford University Press; 2016.

35. Cubist Pharmaceuticals LLC. A prospective, randomized, double-blind, multicenter, phase 3 study to assess the safety and efficacy of intravenous ceftolozane/tazobactam compared with meropenem in adult patients with ventilated nosocomial pneumonia, in clinical study report. 2018: Data on File.

36. Schaffer SK, et al. Assessing the value of new antibiotics: additional elements of value for health technology assessment decisions. London: Office of Health Economics; 2017.

37. Merck \& Co. Inc., K., NJ, USA, Program to assess ceftolozane/tazobactam susceptibility (PACTS) database. 2019. 